ICMB21

\title{
Mould risk assessments in remediated Australian residential buildings
}

\author{
Leela Kempton $^{\mathrm{a} *}$, Georgios Kokogiannakis ${ }^{\mathrm{a}}$, Paul Cooper ${ }^{\mathrm{a}}$ \\ ${ }^{a}$ Sustainable Buildings Research Centre (SBRC), University of Wollongong, Australia
}

\begin{abstract}
A cohort of 233 residential properties with recently remediated mould issues were investigated to understand remediation methods employed and identify factors contributing to mould growth. The root cause and success of remediation was explored for a subset of 30 of the properties. The study showed that remediation without sufficiently addressing the root cause of mould issues is not effective in preventing mould growth from reoccurring in the short term. Subsequently, indoor environmental conditions were monitored for five (5) of these properties over the course of a year, to identify contributing factors to mould growth. Humidity levels in all properties were elevated, with mould affected properties experiencing bedroom humidity levels above $80 \%$ for between $7 \%$ and $45 \%$ of the time. These conditions were evaluated against mould risk indicators in various Standards/guidelines, however none of these indicators were able to reliably predict the risk of mould occurrence in the specific cohort of our study.
\end{abstract}

Peer-review under the responsibility of the organizing committee of the ICMB21.

Keywords: Residential buildings; mould; relative humidity; remediation; monitoring.

\section{Introduction/Background}

To effectively evaluate remediation strategies for mould, it is important to understand the causes, contributing factors and environment in which the growth of mould is occurring. The aim of this study was to investigate influencing factors on mould growth in dwellings. Properties which had recently undergone mould remediation efforts were used to identify characteristics linked to increased risk of mould growth, as well as evaluate the effectiveness of remediation strategies. We also undertook longitudinal monitoring for a longer term analysis of the moisture dynamics within typical residential buildings. Although the detailed monitoring component of this study was limited to a small number of properties, it nevertheless provides an opportunity to identify methods for predicting the risk of future mould growth.

\section{Method}

The properties involved in this study were part of a larger cohort of buildings in Sydney, Australia that had recently been involved in a mould remediation program. Reports from the remediation process for 233 of the properties in this cohort were analysed to understand the most common remediation methods employed and the most frequent contributing factors to mould growth assessed. From these reports, a cohort of 30 were chosen to have a detailed follow up inspection conducted. The selection of the 30 properties was based on the severity of the mould, the underlying causes initially identified and the remediation work conducted, ensuring that the 30 properties were representative of issues identified. Inspections were conducted in November 2017, approximately 6-18 months following the remediation undertaken. This review specifically targeted the possible causes of the mould growth based on assessment of visible mould, building features and occupant usage and identified any regrowth of mould in properties remediated to assess the appropriateness of the remediation methods used.

Finally, longitudinal monitoring was carried out on five dwellings (5) chosen from the dwellings inspected from August 2018 to August 2019. These properties were chosen based on the extent of visible mould present and underlying cause identified, whilst ensuring that they were representative of the wider cohort in terms of building typology, location and underlying mould cause. A mixture of typologies such as low rise apartment, high rise apartment, terrace and townhouse were selected.

As the main aim of the study was to understand issues of condensation and mould throughout the building, the key component of the monitoring involved temperature and relative humidity monitoring throughout the property, as well as of the external conditions. Hobo UX-100 loggers were used for these measurements (accuracy: temperature $\pm 0.21^{\circ} \mathrm{C}$ at $-20^{\circ}$ to $70^{\circ} \mathrm{C}, 0.024^{\circ} \mathrm{C}$ at $25^{\circ} \mathrm{C}$; and relative humidity $\pm 3.5 \%$ at $15 \%$ to $95 \%, 0.07 \%$ at $25^{\circ} \mathrm{C}$ ). Surface temperatures were also vital in understanding the risk of condensation occurring on the walls. The surface temperatures were monitored using an assembly of i-Buttons ${ }^{\mathrm{TM}}$ installed facing the affected wall and insulated from the surrounding air (accuracy: $\pm 0.5^{\circ} \mathrm{C}$ at $-20^{\circ} \mathrm{C}$ to $+85^{\circ} \mathrm{C}$ ). The indoor air and wall temperatures were used with external temperature conditions to assess the potential risk of condensation occurring.

\section{Results}

Remediation reports were reviewed for 233 properties that had undergone mould remediation including cleaning by contractors during late 2016-early 2017. The reports included details of the type of property, rooms affected by mould, proposed causes of mould, and remediation methods. Mould growth experienced varied from minor patches to extreme large scale growth. The

\footnotetext{
*Corresponding author.+61413492 751. leelak@uow.edu.au
}

(C) The Author(s). This is an open access article distributed under the terms of the Creative Commons Attribution License (CC BY) 4.0 https://creativecommons.org/licenses/by/4.0/, which permits unrestricted use, distribution and reproduction in any medium, provided the original author and source are credited. DOI: 10.14293/ICMB210032 


\section{ICMB21}

average number of rooms affected in these properties was just over 2, indicating that in many situations the mould issue was not confined to a single location and that the underlying cause of the mould was unlikely to be localised water damage. Most properties experienced mould growth in bathrooms (78\%), while a smaller proportion of bedrooms were affected (35\%). The causes identified in the initial reports and from the building inspections are provided in Table 1. In comparison, the building inspection reports conducted on the 30 properties highlighted inadequate ventilation at a contributing factor to the mould issue in nearly all of the properties (Table 1). This assessment was based on observation of the ventilation equipment available (e.g. exhaust fans, operable windows) within the properties as well as the mould issues present. Mould was found to have already returned in 12 out of the 30 properties inspected $(40 \%)$.

Table 1: Assessment of the cause of mould (some properties had more than one cause of mould).

\begin{tabular}{|l|c|c|c|c|}
\hline \multirow{2}{*}{} & \multicolumn{2}{|c|}{ Reports on 233 properties } & \multicolumn{2}{c|}{30 Building Inspections } \\
\cline { 2 - 5 } & No. & $\%$ affected & No. & $\%$ affected \\
\hline Ventilation & 165 & $70.8 \%$ & 28 & $93.3 \%$ \\
Ventilation as sole cause of mould & 55 & $23.6 \%$ & 21 & $70.0 \%$ \\
\hline Some form of leak identified & 51 & $21.9 \%$ & 4 & $13.3 \%$ \\
$\quad$ Leak as the sole cause of mould & 13 & $5.6 \%$ & 2 & $6.7 \%$ \\
\hline External Drainage issues (e.g. gutters, downpipes) & 4 & $1.7 \%$ & & \\
\hline Lack of Natural Light & 35 & $15.0 \%$ & & \\
\hline Rising Damp/subfloor moisture & 17 & $7.3 \%$ & 1 & $3.3 \%$ \\
\hline Internal clothes drying/ Dryer use & & & 4 & $13.3 \%$ \\
\hline Other (Not specified) & 35 & $15.0 \%$ & & \\
\hline
\end{tabular}

Longitudinal monitoring of five properties found that the properties experienced low winter temperatures outside the generally accepted comfort levels, with temperatures in winter below $18^{\circ} \mathrm{C}$ in bedrooms for between 79 and $100 \%$ of the time. High levels of relative humidity were also found in many of the properties, with the humidity in bathrooms above $80 \%$ for between $9 \%$ and $38 \%$ of the time. Humidity levels in the bedroom were above $80 \%$ for between $1 \%$ and $45 \%$ of the time, although for the properties experiencing mould issues this was between $7 \%$ and $45 \%$ of the time. These elevated relative humidity levels increase the risk of surface condensation which can cause mould issues. Surface temperature and humidity levels were elevated in all properties, but were particularly high in areas with extensive mould growth.

The data monitored was evaluated against some of the available mould risk indicators in BS5250 [1], ISO13788 [2], CIBSE Guide A [3] and ASHRAE 160 [4], with the results provided in Table 2. However for the specific cohort of five properties in our study, these indicators were not able to reliably predict the risk of mould occurrence. The complex interactions between occupant behaviour and indoor environment, and how these can be used to estimate the risk of mould occurrence requires further investigation.

Table 2: Summary of monitored properties performance against mould risk indicators ("Y": exceeding the standard indicator for mould risk; "N": meets the standard requirements)

\begin{tabular}{|c|c|c|c|c|c|c|}
\hline Property & & 1 & 2 & 3 & 4 & 5 \\
\hline Audited Mould Severity Rating (from Table 5) & & 0 & 1 & 2 & 3 & 4 \\
\hline $\begin{array}{l}\text { Winter Bedroom Average Temperature } \\
\left(\text { Low }-<16^{\circ} \mathrm{C} \text {, Med }-16-18^{\circ} \mathrm{C} \text {, High }->18^{\circ} \mathrm{C}\right)\end{array}$ & & $\begin{array}{l}\text { MEDIUM } \\
\left(17.1^{\circ} \mathrm{C}\right)\end{array}$ & $\begin{array}{c}\text { LOW } \\
\left(15.9^{\circ} \mathrm{C}\right)\end{array}$ & $\begin{array}{l}\text { MEDIUM } \\
\left(17.1^{\circ} \mathrm{C}\right)\end{array}$ & $\begin{array}{c}\text { LOW } \\
\left(15.4^{\circ} \mathrm{C}\right)\end{array}$ & $\begin{array}{l}\text { MEDIUM } \\
\left(17.1^{\circ} \mathrm{C}\right)\end{array}$ \\
\hline \multirow[t]{3}{*}{ BS5250: Bathroom Humidity $>70 \%$ for 3 days } & $>5 \%$ & Y & $\mathrm{Y}$ & Y & Y & Y \\
\hline & $>10 \%$ & $\mathrm{~N}$ & $\mathrm{Y}$ & Y & Y & Y \\
\hline & $>15 \%$ & $\mathrm{~N}$ & $\mathrm{Y}$ & $\mathrm{N}$ & $\mathrm{N}$ & $\mathrm{Y}$ \\
\hline \multirow[t]{3}{*}{ BS5250: Bedroom Humidity $>70 \%$ for 3 days } & $>5 \%$ & $\mathrm{~N}$ & $\mathrm{Y}$ & Y & $\mathrm{Y}$ & Y \\
\hline & $>10 \%$ & $\mathrm{~N}$ & $\mathrm{~N}$ & Y & $\mathrm{N}$ & Y \\
\hline & $>15 \%$ & $\mathrm{~N}$ & $\mathrm{~N}$ & Y & $\mathrm{N}$ & $\mathrm{Y}$ \\
\hline ISO13788 Surface humidity & & $\mathrm{Y}$ & $\mathrm{N}$ & Y & $\mathrm{N}$ & Y \\
\hline ASHRAE 160 & & $\mathrm{~N}$ & $\mathrm{~N}$ & Y & $\mathrm{N}$ & Y \\
\hline
\end{tabular}

\section{References}

[1] British Standards Institute, BSI (2011), "BS 5250: 2011 Code of practice for control of condensation in buildings". London.

[2] ISO (2012), "ISO 13788: 2012 Hygrothermal performance of building components and building elements-Internal surface temperature to avoid critical surface humidity and interstitial condensation-Calculation methods", Brussels.

[3] CIBSE (2019), "CIBSE Guide A: Environmental Design", The Chartered Institution of Building Services Engineers, 8th edition, Incorporating corrections as of May 2019.

[4] ASHRAE, (2016), "ASHRAE Standard 160-2016 Criteria for Moisture Control Design Analysis in Buildings", American Society of Heating, Refrigerating and Air-Conditioning Engineers, Atlanta. 